\title{
DELINEAMENTOS E ANÁLISES DE EXPERIMENTOS COM CAFEEIROS $\left({ }^{*}\right)$
}

C. G. Fraga JR. e A. Conagin, engenheiros-agrônomo's, Seção de T'écnica Experimental, Instituto Agronômico

\section{R E S U M O}

Os autores apresentam, de forma sueinta, os principais delineamentos e processos de análise estatística utilizados na experimentação com o eafeeiro no Instituto Agronômico.

Consideram quatro grupos de experimentos: experimentos de adubação, ensaios de variedades, ensaios de progênies e outros ensaios.

No primeiro grupo diseutem, além dos experimentos mais antigos com delineamentos sistemáticos, outros mais recentes, já com delineamentos casualizados. Consideram um experimento fatorial, o qual forneceu resultados conclusivos em poucos anos, indicando a conveniência de serem mudados alguns tratamentos.

No segundo, discutem uma experiência sistemática de variedades analisada por W. L. Stevens (3).

No terceiro, discutem a evolução dos delineamentos usados para a comparação de progênies e, finalmente, no quarto grupo, consideram os delineamentos para experimentos de espaçamento e outros, assim como os estudos sôbre a eficiência de parcelas com tamanhos diferentes.

\section{1 - INTRODUÇÃO}

O primeiro experimento com café realizado no Instituto Agronômico foi instalado por Dafert em 1891 e constou do plantio, lado a lado, de duas linhas com Bourbon e quatro outras com o cafeeiro comum. Para suas conclusões êle se baseou em resultados de cinco anos de produçãa.

Em 1894 outro experimento foi instalado para estudar adubação em terra fraca e pobre em húmus e em terra fértil e humosa. Cada um dos ensaios constou de sete linhas paralelas de cafeeiros, em que foram comparados com a testemunha (sem adubo) plantada em linhas alternadas, os três tratamentos seguintes: estêrco, adubação mineral e adubação minerál mạais estêrco (1).

(*) Trabalho apresentado no III Simpósio Internacional de Biometria, realizado em Campinas, entre $4: 10$ de Julho de 1955.

Apresentamos os nossos sinceros agradecimentos as Seçoos de Café e Genética do Instituto Agronômico, que nos permitiram o uso de dados, a maioria dos quais ainda näo publicada

Recebido para publicaçấo em 24 de dezembro de 1955. 


\section{2 - ENSAIOS DE ADUBAÇÃO}

O estudo racional de adubaçãa do cafeeiro no Instituto Agronômico foi iniciado em 1928-29 com o experimento instalado por Theodureto de Camargo, em Campinas. Com a aquisição, pelo Instituto, de duas estações experimentais em região cafeeira (Ribeirão Prêto e Pindorama), essa experimentação com adubos foi a elas estendida. Na instalação dêstes experimentos foram considerados tratamentos semelhantes aos utilizados em Campinas ; o delineamento dos ensaios foi, no entanto, melhorado. Ŵstes três experimentos forneceram as primeiras informações de valor relativas à adubação do cafeeiro e deixaram entrever a necesidade de se investigar outros pontes, como por exemplo aquêle das doses, que pareciam ser insuficientes nesses ensaios. Outro ponto de interêsse consistia em investigar adubações para manutenção e aumento de produção em cafèzais já formados, independentemente daquelas visando à formação de cafèzais novos. Tendo em vista êstes pontos, novos ensaios foram instalądos. Também o aumento da rêde de estações experimentais incluiu no esquema de experimentação com cafeeiros as fazendas de Jaú, Mococa e Monte Alegire: 0 número de experimentos com fertilizantes ficou assim bastante aumentado; êstes experimentos são, no entanto, todos relativamente recentes, não existindo para a maioria dêles um número de colheitas suficiente para tornar interessante uma análise cuidadosa dos resultados obtidos. Os principais dentre êstes ensaios foram considerados em seus detalhes, obedecida a ordem cronológica.

\section{1 - ENSAIO DE ADUBACÃO EM CAMPINAS}

Êste ensaio foi iniciado no ano agrícola de 1928-29 tendo sido plantado em um pasto velho de terra roxa misturada. O experimento constou de 24 . tratamentos que podem ser agrupados em quatro séries : orgânica, azotada, fosfatada e potássica. Os 120 canteiros da experiência eram grandes (800 $\mathrm{m}^{2}$, ou $40 \times 20 \mathrm{~m}$ ) comportando cada um 50 covas com dois pés por cova. Os tratamentos, agrupados por séries, estão transcritos nos quadros 1 e 2 .

A disposição foi sistemática, os componentes das séries sendo mais ou: menos agrupados e distribuídos irregularmente, o que tornou impossível a consideração de blocos compactos. A ausência de blocos e a falta de sorteio criam dificuldades para se efetuar a análise estatística dos resultados e também podem afetar os resultados, devido a confundimento do efeito de tratamentos com o do terreno.

As produções cresceram até atingir um máximo entre os $8 .^{\circ}$ e $100^{\circ}$ anos, mas parecem não ter estabilizado, existindo a partir dêsses anos uma tendência para decrescer. Como a experiência foi arrancada em 1944, êsse aspecto não pôde ser verificado. A partir do $4 .^{\circ}$ ano as produções passaram a ser alternadas $\left({ }^{1}\right)$, razão pela qual na análise dêstes e de outros experimentos com o cafeeiro foram sempre considerados pares de anos. 
Quadro 1.-Ensaio de adubação do cafeeiro, em Cámpinas: 'Médias de cinco repetiçбès por biênios, em $\mathrm{kg}$ de café em côco, por canteiro at.

\begin{tabular}{|c|c|c|c|c|c|c|c|}
\hline .. Tratamentos & $\begin{array}{l}1931 \\
1932\end{array}$ & $\begin{array}{l}1933 \\
1934\end{array}$ & $\begin{array}{l}1935 \\
1936\end{array}$ & $\begin{array}{l}1937 \\
1938\end{array}$ & $\begin{array}{l}1939 \\
1940\end{array}$ & $\begin{array}{l}1941 \\
1942\end{array}$ & $\begin{array}{l}1943 \\
1944\end{array}$ \\
\hline Orgânico & $\mathrm{kg}$ & $k g$ & $\mathrm{~kg}$ & $\operatorname{lgg}$ & $k g$ & $\mathrm{~kg}$ & $k g$ \\
\hline $\begin{array}{l}\text { Palha de cafe + adub. química } \\
\text { Palha de café } \\
\text { Estêrco + adub. química } \\
\text { Estêrco vorde + adub. química } \\
\text { Adub. verde } \\
\text { Adub verde } \\
\text { Tankage } \\
\text { Nitrophoska "C" }\end{array}$ & $\begin{array}{l}90 \\
60 \\
97 \\
90 \\
56 \\
35 \\
67 \\
60\end{array}$ & $\begin{array}{r}241 \\
231 \\
199 \\
167 \\
110 \\
90 \\
126 \\
144\end{array}$ & $\begin{array}{r}303 \\
262 \\
253 \\
188 \\
129 \\
94 \\
142 \\
172\end{array}$ & $\begin{array}{l}428 \\
380 \\
404 \\
300 \\
239 \\
156 \\
233 \\
264\end{array}$ & $\begin{array}{l}417 \\
368 \\
364 \\
266 \\
252 \\
211 \\
230 \\
233\end{array}$ & $\begin{array}{r}212 \\
175 \\
159 \\
120 \\
86 \\
67 \\
76 \\
87\end{array}$ & $\begin{array}{l}306 \\
267 \\
252 \\
180 \\
172 \\
117 \\
138 \\
161\end{array}$ \\
\hline \multicolumn{8}{|l|}{ Potássio } \\
\hline $\begin{array}{l}\text { Dose grande } \mathrm{K}_{2} \mathrm{O} \\
\text { Dose grande } \mathrm{K}_{2} \mathrm{O}(\mathrm{MgO}) \\
\text { Dose média } \mathrm{K}_{2} \mathrm{O} \\
\text { Dose pequena } \mathrm{K}_{2} \mathrm{O} \\
\text { Dose pequena } \mathrm{K}_{2} \mathrm{O}(\mathrm{MgO}) \\
\text { Sem potássio }\end{array}$ & $\begin{array}{l}62 \\
60 \\
53 \\
59 \\
59 \\
61\end{array}$ & $\begin{array}{l}160 \\
160 \\
142 \\
166 \\
149 \\
144\end{array}$ & $\begin{array}{l}231 \\
225 \\
196 \\
188 \\
174 \\
160\end{array}$ & $\begin{array}{r}382 \\
329 \\
306 \\
294 \\
284 \\
201\end{array}$ & $\begin{array}{l}350 \\
292 \\
262 \\
258 \\
258 \\
188\end{array}$ & $\begin{array}{r}141 \\
133 \\
85 \\
86 \\
83 \\
52\end{array}$ & $\begin{array}{l}252 \\
248 \\
169 \\
156 \\
168 \\
110\end{array}$ \\
\hline \multicolumn{8}{|l|}{ Fósforo } \\
\hline $\begin{array}{l}\text { Dose grande } \mathrm{P}_{2} \mathrm{O}_{5} \\
\text { Dose média } \mathrm{P}_{2} \mathrm{O}_{5} \\
\text { Dose pequena } \mathrm{P}_{2} \mathrm{O}_{5} \\
\text { Sem fósforo }\end{array}$ & $\begin{array}{l}60 \\
50 \\
53 \\
35\end{array}$ & $\begin{array}{l}149 \\
139 \\
130 \\
120\end{array}$ & $\begin{array}{l}187 \\
177 \\
169 \\
148\end{array}$ & $\begin{array}{l}289 \\
284 \\
267 \\
230\end{array}$ & $\begin{array}{l}255 \\
259 \\
240 \\
210\end{array}$ & $\begin{array}{l}76 \\
73 \\
81 \\
59\end{array}$ & $\begin{array}{l}149 \\
166 \\
160 \\
130\end{array}$ \\
\hline \multicolumn{8}{|l|}{ Nitrogênio } \\
\hline $\begin{array}{l}\text { Dose grande N amon. } \\
\text { Dose grande N nítrico } \\
\text { Dose pequena N amon. } \\
\text { Dose pequena N nítrico } \\
\text { Sem nitrogênio }\end{array}$ & $\begin{array}{l}54 \\
53 \\
64 \\
52 \\
52\end{array}$ & $\begin{array}{l}123 \\
139 \\
160 \\
135 \\
162\end{array}$ & $\begin{array}{l}152 \\
167 \\
194 \\
146 \\
173\end{array}$ & $\begin{array}{l}258 \\
284 \\
307 \\
248 \\
260\end{array}$ & $\begin{array}{l}247 \\
256 \\
284 \\
249 \\
240\end{array}$ & $\begin{array}{l}77 \\
86 \\
97 \\
77 \\
79\end{array}$ & $\begin{array}{l}154 \\
169 \\
163 \\
149 \\
143\end{array}$ \\
\hline Sem adubo -..-- & 32 & 106 & 101 & 144 & 139 & 36 & 86 \\
\hline
\end{tabular}

Os tratamentos piores (sem adubo, sem azôto, sem fósforo e sem potássio) apresentaram variabilidade maior que os demais : os quatro tratamentos mais produtivos (palha de café mais adubação química, estêrco mais adubação química, palha de café e dose grande de potássio) apresentaram variabilidade bienal média, inferior à do resto da experiência. $\mathbf{E m}$ um mesmo tratamento essa variabilidade parece erescer com a produção, de forma que o coeficiente de variação para um tratamento permanece mais ou menos constante. As produções, a partir dos segundos e terceiros biênios, já mostravam nìtidamente o efeito dos tratamentos, os melhores e os piores se destacando, resultados êsses que perduraram a partir dessa época.

Neste ensaio foi possível verificar o efeito dos adubos orgânicos aumentando a produção (palha de café e estêrco, principalmente quando complementados quìmicamente); houve ainda uma reação nítida ao potássio. Êsses resultados foram confirmados em experiências posteriores, instaladas em solos afins. 
Quadro 2.-Ensaio de ałubaģão do cafeeiro, em Campinas. Desvio padrão e Coeficiente de Variação

\begin{tabular}{|c|c|c|c|c|c|c|c|c|c|c|c|c|c|c|}
\hline \multirow{2}{*}{ Tratamentos } & \multicolumn{2}{|c|}{$31-32$} & \multicolumn{2}{|c|}{$33-34$} & \multicolumn{2}{|c|}{$35-36$} & \multicolumn{2}{|c|}{$37-38$} & \multicolumn{2}{|c|}{$39-40$} & \multicolumn{2}{|c|}{$41-42$} & \multicolumn{2}{|c|}{$43-44$} \\
\hline & $\sigma$ & CV & $\sigma$ & $\mathrm{CV}$ & $\sigma$ & CV & $\sigma$ & $\mathrm{CV}$ & $\sigma$ & $\mathrm{CV}$ & $\sigma$ & CV & $\sigma$ & $\mathrm{CV}$ \\
\hline Oroanico & & $\%$ & & $\%$ & & $\%$ & & $\%$ & & $\%$ & & $\%$ & & $\%$ \\
\hline 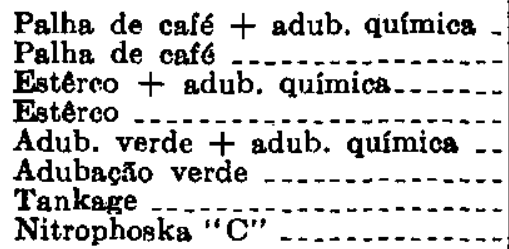 & $\begin{array}{r}\mathbf{5} \\
11 \\
15 \\
21 \\
14 \\
9 \\
14 \\
10\end{array}$ & $\begin{array}{r}5 \\
18 \\
15 \\
24 \\
26 \\
26 \\
20 \\
16\end{array}$ & $\begin{array}{r}7 \\
22 \\
39 \\
33 \\
47 \\
20 \\
40 \\
31\end{array}$ & $\begin{array}{r}3 \\
9 \\
19 \\
19 \\
43 \\
23 \\
31 \\
22\end{array}$ & $\begin{array}{l}30 \\
31 \\
47 \\
27 \\
61 \\
29 \\
42 \\
52\end{array}$ & $\begin{array}{l}10 \\
12 \\
19 \\
14 \\
47 \\
30 \\
30 \\
30\end{array}$ & $\begin{array}{l}25 \\
36 \\
60 \\
46 \\
96 \\
24 \\
44 \\
62\end{array}$ & $\begin{array}{r}6 \\
9 \\
15 \\
15 \\
40 \\
15 \\
19 \\
23\end{array}$ & $\begin{array}{l}29 \\
18 \\
43 \\
58 \\
67 \\
34 \\
52 \\
51\end{array}$ & $\begin{array}{r}7 \\
5 \\
12 \\
22 \\
26 \\
16 \\
23 \\
22\end{array}$ & $\begin{array}{l}38 \\
18 \\
36 \\
29 \\
42 \\
28 \\
26 \\
26\end{array}$ & $\begin{array}{l}18 \\
10 \\
23 \\
24 \\
49 \\
42 \\
34 \\
29\end{array}$ & $\begin{array}{l}19 \\
35 \\
42 \\
20 \\
52 \\
27 \\
35 \\
47\end{array}$ & $\begin{array}{r}6 \\
13 \\
17 \\
11 \\
30 \\
23 \\
25 \\
29\end{array}$ \\
\hline \multicolumn{15}{|l|}{ Polássio } \\
\hline $\begin{array}{l}\text { Dose grande } \mathrm{K}_{2} \mathrm{O} \\
\text { Dose grande } \mathrm{K}_{2} \mathrm{O}(\mathrm{MgO}) \\
\text { Dose media } \mathrm{K}_{2} \mathrm{O} \\
\text { Dose pequena } \mathbf{K}_{2} \mathrm{O} \\
\text { Dose pequena } \mathbf{K}_{2} \mathrm{O}(\mathrm{MgO}) \\
\text { Sem potássio }\end{array}$ & $\begin{array}{r}8 \\
13 \\
5 \\
11 \\
8 \\
18\end{array}$ & $\begin{array}{r}12 \\
22 \\
9 \\
19 \\
13 \\
61\end{array}$ & $\begin{array}{l}33 \\
27 \\
34 \\
27 \\
30 \\
38\end{array}$ & $\begin{array}{l}21 \\
17 \\
24 \\
16 \\
20 \\
26\end{array}$ & $\begin{array}{l}31 \\
49 \\
30 \\
28 \\
47 \\
70\end{array}$ & $\begin{array}{l}13 \\
22 \\
15 \\
15 \\
27 \\
44\end{array}$ & $\begin{array}{l}57 \\
30 \\
43 \\
55 \\
32 \\
\mathbf{9 2}\end{array}$ & $\begin{array}{r}15 \\
9 \\
14 \\
19 \\
11 \\
45\end{array}$ & $\begin{array}{l}51 \\
27 \\
44 \\
39 \\
34 \\
81\end{array}$ & $\begin{array}{r}14 \\
99 \\
17 \\
15 \\
13 \\
43\end{array}$ & $\begin{array}{l}45 \\
17 \\
24 \\
20 \\
19 \\
29\end{array}$ & $\begin{array}{l}32 \\
12 \\
28 \\
23 \\
22 \\
54\end{array}$ & $\begin{array}{l}23 \\
29 \\
40 \\
21 \\
24 \\
47\end{array}$ & $\begin{array}{r}9 \\
12 \\
24 \\
13 \\
14 \\
43\end{array}$ \\
\hline \multicolumn{15}{|l|}{ Fósjoto } \\
\hline $\begin{array}{l}\text { Dose grande } \mathrm{P}_{2} \mathrm{O}_{5} \\
\text { Dose média } \mathrm{P}_{2} \mathrm{O}_{5} \\
\text { Dose pequena } \mathbf{P}_{\mathbf{2}} \mathrm{O}_{5} \\
\text { Sem fosforo }\end{array}$ & $\begin{array}{r}10 \\
5 \\
9 \\
12\end{array}$ & $\begin{array}{r}16 \\
9 \\
16 \\
34\end{array}$ & $\begin{array}{l}43 \\
26 \\
29 \\
55\end{array}$ & $\begin{array}{l}29 \\
19 \\
23 \\
46\end{array}$ & $\begin{array}{l}65 \\
26 \\
35 \\
59\end{array}$ & $\begin{array}{l}34 \\
15 \\
21 \\
40\end{array}$ & $\begin{array}{l}49 \\
40 \\
47 \\
87\end{array}$ & $\begin{array}{l}17 \\
14 \\
18 \\
38\end{array}$ & $\begin{array}{l}33 \\
43 \\
27 \\
97\end{array}$ & $\begin{array}{l}13 \\
16 \\
11 \\
46\end{array}$ & $\begin{array}{l}10 \\
30 \\
14 \\
52\end{array}$ & $\begin{array}{l}12 \\
41 \\
17 \\
88\end{array}$ & $\begin{array}{l}16 \\
30 \\
30 \\
75\end{array}$ & $\begin{array}{l}11 \\
18 \\
19 \\
57\end{array}$ \\
\hline \multicolumn{15}{|l|}{ Nitrogenio } \\
\hline $\begin{array}{l}\text { Dose grande } \mathbf{N} \text { amon. } \\
\text { Dose grande } \mathbf{N} \text { nítrico } \\
\text { Dose pequena } \mathbf{N} \text { amon. } \\
\text { Dose pequena } \mathbf{N} \text { nítrica } \\
\text { Sem nitrogentio }\end{array}$ & $\begin{array}{r}7 \\
7 \\
9 \\
8 \\
17\end{array}$ & $\begin{array}{l}14 \\
13 \\
14 \\
15 \\
33\end{array}$ & $\begin{array}{l}34 \\
25 \\
36 \\
52 \\
67\end{array}$ & $\begin{array}{l}27 \\
18 \\
23 \\
39 \\
41\end{array}$ & $\begin{array}{l}50 \\
45 \\
62 \\
57 \\
75\end{array}$ & $\begin{array}{l}33 \\
27 \\
32 \\
39 \\
43\end{array}$ & $\begin{array}{l}29 \\
43 \\
64 \\
49 \\
67\end{array}$ & $\begin{array}{l}11 \\
15 \\
21 \\
20 \\
26\end{array}$ & $\begin{array}{l}40 \\
34 \\
46 \\
42 \\
50\end{array}$ & $\begin{array}{l}16 \\
13 \\
16 \\
17 \\
21\end{array}$ & $\begin{array}{l}29 \\
27 \\
26 \\
26 \\
29\end{array}$ & $\begin{array}{l}37 \\
31 \\
28 \\
34 \\
37\end{array}$ & $\begin{array}{l}11 \\
36 \\
22 \\
29 \\
36\end{array}$ & $\begin{array}{r}7 \\
\mathbf{2 1} \\
14 \\
19 \\
\mathbf{2 5}\end{array}$ \\
\hline Sem adubo & 14 & 44 & 43 & 40 & 45 & 45 & 76 & 53 & 76 & 54 & 26 & 72 & 54 & 63 \\
\hline
\end{tabular}

\section{2 - ENSAIOS DE ADUBAÇÃO DE RIBEIRAO PRETO E PINDORAMA}

Os estudos referentes à adubação foram em seguida estendidos às estações experimentais de Ribeirão Prêtc (terra roxa legítima) e Pindorama (terra arenosa). Nestas experiências, muito mais recentes (1935), as adubações foram agrupadas em cinco séries : orgânica mais mineral, orgânica, fosfatada, azotada e potássica. Tôdas elas eram formadas por cinco tratamentos com cinco repetições, em quadrado latino. Dos cinco tratamentos de cada série, um dêles, o contrôle, sem adubo, era comum a tôdas as séries. Nas séries de adubos químicos os quatro tratamentos restantes eram constituídos por fórmulas combinando quatro níveis de um dos adubos a níveis fixos dos dois outros. Na série orgânica foram estudados três adubos orgânicos. A distância foi de $3,50 \times .3,50 \mathrm{~m}$ e os canteiros compostos de 25 covas.

$O$ ensaio de Ribeirão Prêto, devido ao uso de dosagens pouco elevadas dos adubos químicos, à morte đe numerosas plantas e à pouca produção, foi mais tarde substituído por outro. As produções do ensaio de Pindorama 
durante seis biênios não indicam a tendência usual de erescimento de produção e, mesmo em alguns tratamentos, como nos sem adubo, talvez tenha havido um decréscimo. Uma parte dêste ensaio foi arrancada há alguns anos, a parte correspondente às adubações químicas existindo até hoje. Outro característico dêste ensaio, que é semelhante ao apresentado no Ensaio de Adubação de Campinas, refere-se à-variabilidade. Esta é maior nos biênios de grande produção (série orgânica mais adubos minerais, quadros 3,4 e 5).

Quadro 3.-Ensaio de adubação do cafeeiro em Pindorama. Produções bienais e totais, da série orgânica + adubação química, em quilogramas de café em côco por canteiro

\begin{tabular}{|c|c|c|c|c|c|c|c|}
\hline Tratamentos & $39-40$ & $41-42$ & $43-44$ & $45-46$ & $47-48$ & $49-50$ & 'Totais \\
\hline & $k g$ & $k g$ & $k g$ & $k_{\theta}$ & $k\}$ & $\mathrm{kg}$ & $k g$ \\
\hline 1. Estêrco + adub. química & 438 & 709 & 295 & 674 & 686 & 286 & 3088 \\
\hline 2. Palba + adub química & 389 & 596 & 273 & 620 & 675 & 296 & 2849 \\
\hline 3. Adub. verde + adub. química & 474 & 601 & 342 & 579 & 631 & 253 & 2880 \\
\hline 4. Adubação química & 367 & 736 & 263 & 540 & 529 & 259 & 2694 \\
\hline 5. Sem adubo $\ldots \ldots$ & 338 & 636 & 243 & 466 & 375 & 165 & 2223 \\
\hline
\end{tabular}

\section{D.m.s. $=289$}

Quadro 4.-Ensaio de adubação do cafeeiro em Pindorama. Análises estatísticas por biênios da série orgânica + adubação química (Quadrados médios)

\begin{tabular}{|c|c|c|c|c|c|c|c|}
\hline Fonte de Variaçīo & G.L. & $39-40$ & $41-42$ & $43-44$ & $40-46$ & $47-48$ & $49-50$ \\
\hline $\begin{array}{l}\text { E. colunas } \\
\text { E. linhas } \\
\text { E. tratamentos } \\
\text { Frro }\end{array}$ & $\begin{array}{r}4 \\
4 \\
4 \\
12\end{array}$ & $\begin{array}{c:}45 \\
316^{*} \\
595^{* *} \\
63\end{array}$ & $\begin{array}{c}305 \\
1915^{* *} \\
813 \\
305\end{array}$ & $\begin{array}{c}177^{* *} \\
249^{* *} \\
286^{* *} \\
21\end{array}$ & $\begin{array}{c}544^{* *} \\
1078^{* *} \\
1247^{* *} \\
69\end{array}$ & $\begin{array}{c}827^{* *} \\
437 \\
3377^{* *} \\
148\end{array}$ & $\begin{array}{l}285 \\
495^{*} \\
538^{* *} \\
97\end{array}$ \\
\hline Coef. de Variação & & 10 & 13 & 8 & 7 & 10 & 19 \\
\hline
\end{tabular}

Quadro 5.-Ensaio de adubação do cafeeiro, em Pindorama. Análise estatística

\begin{tabular}{|c|c|c|c|c|}
\hline Foute de Variação & Soma de Quadrados & G.L. & Quadirados & Médios \\
\hline 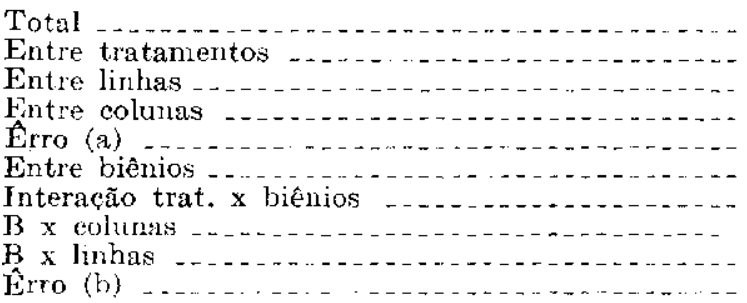 & $\begin{array}{r}206.393,79 \\
14.070,93 \\
12.967,90 \\
4.423,28 \\
3.518,90 \\
143.835,81 \\
13.353,91 \\
4.308,76 \\
4.997,01 \\
4.917,30\end{array}$ & $\begin{array}{r}149 \\
4 \\
4 \\
4 \\
12 \\
5 \\
20 \\
20 \\
20 \\
60\end{array}$ & & $\begin{array}{r}3.517,73 \\
3.241,22 \\
1.105,82 \\
293,24 \\
28.767,16 \\
667,69 \\
215,44 \\
249,85 \\
81,95\end{array}$ \\
\hline
\end{tabular}

O quadro 3 inclui produções totais por biênios, dos vários tratamentos, e o quadro 4, a respectiva análise da variância e os coeficientes de variação. Nota-se uma certa estabilidade dêstes, o que indicaria, talvez. a conveniência de uma transformação dos dados. 
O quadro 5 contém a análise conjunta das produções dos seis biênios. Além dos tratamentos diferirem significativamente, também houve diferenças entre os biênios e a interação biênios $x$ tratamentos foi significativa. Foi feito o estudo desta interação decompondo a segunda parte da análise, calculando-se a função $5 \mathbf{X}_{1}+3 \mathbf{X}_{2}+1 \mathbf{X}_{3}-1 \mathbf{X}_{4}-3 \mathbf{X}_{5}-5 \mathbf{X}_{6}$ onde $\mathbf{X}_{1}, \mathbf{X}_{2}, \mathbf{X}_{3}, \ldots \mathbf{X}_{6}$ são as produções dos canteiros por biênios, respectivamente. Os resultados obtidos na análise da variância são os apresentados no quadro 6 e permitem concluir que só o tratamento palha de café mais adubação química está mantendo a fertilidade.

QCadro 6.--Ensaio de adubação do cafeeiro em Pindorama. Análise da variância do componente linear (tendência)

\begin{tabular}{|c|c|c|c|c|}
\hline Fonte de Variagão & $\begin{array}{l}\text { Somal de: } \\
\text { quadrades }\end{array}$ & (i.l. & $\begin{array}{l}\text { Quadrados } \\
\text { médios }\end{array}$ & F \\
\hline $\begin{array}{l}\text { Totais } \\
\text { C. Iinear (correção) } \\
\text { C. Iinear x Linhus } \\
\text { C. Linear x Colunas } \\
\text { Y. Yirear x Tratamentos } \\
\text { Tiro }\end{array}$ & $\begin{array}{r}957.700 \\
468.431 \\
68.730 \\
98.247 \\
260.081 \\
62.211\end{array}$ & $\begin{array}{r}25 \\
1 \\
4 \\
4 \\
4 \\
12\end{array}$ & $\begin{array}{r}468.431 \\
-\quad 17.182 \\
24.562 \\
63.020 \\
5.184\end{array}$ & $\begin{array}{r}7,20 \\
3,31^{*} \\
4,73^{*} \\
12,54^{* *}\end{array}$ \\
\hline
\end{tabular}

Totais: $T_{1}=450,2 \quad T_{2}=-118,6 \quad T_{3}=780,7 \quad T_{4}=882,2 \quad T_{5}=1.427,6$

Para colocar os resultados na mesma base da análise total é necessário dividir as somas de quadrados por 70 .

Quanto à análise da produção total, os tratamentos contendo adubação orgânica complementada quìmicamente não deferiram entre si, mas foram superiores aos tratamentos com adubação mineral e ao sem adubo. A produção dêste último é inferior à de qualquer um dos outros tratamentos. A comparação entre séries pode ser feita por intermédio dos tratamentos sem adubo. Houve homogeneidade de variância para as produções totais das diferentes séries.

\section{3 - ENSAIO DE ADUBAÇAO NPKE}

Tendo em vista o fracasso do ensaio anterior em Ribeirão Prêto, foi êle substituído em 1948 por um novo experimento, o qual também foi repetido em Mococa. Os tratamentos $\mathbf{n}, \mathbf{p}, \mathbf{k}$ e e (estêrco), constituiram um fatorial $2^{4}$ com delineamento em quadrado quase-latino $8 \times 8$, com quatro repetições e fusão total da interação NPKE nas colunas e 1/4 das interações NPK, NPE, PKE e NKE nas linhas. Os canteiros contém nove covas úteis, plantadas a $2,70 \times 2,50 \mathrm{~m}$, a quatro pés por cova.

Quando do plantio, todos os tratamentos deveriam ter recebido 10 quilos de estêrco para a formação das plantas e, a partir do ano seguinte, seriam aplicadas as doses diferenciais do ensaio. Isso, porém, não se verificou, não tendo o tratamento sem adubo (1) recebido a estercação indicada, o que mais tarde veio prejudicar o experimento. 
As produções demonstram nitidamente a existência de três níveis de fertilidade. Tem produção pràticamente nula o tratamento (1) (que não recebeu estercação na cova). A êste seguem-se os tratamentos $\mathbf{p}$, n e np, que só receberam estêrco no plantio. O grupo de maior produção é formado pelos demais tratamentos, os quais receberam $\mathbf{k}$ ou $\mathbf{e}$ ou ambos (Ver quadro 7).

Quadro 7.--Produções de café em côco (unidade $=10$ gramas) de três anos do Ensaio de Adubação NPKE $=2^{4}$, Ribeirão Prêto

\begin{tabular}{|c|c|c|c|c|c|c|c|c|}
\hline$\frac{p k}{15 \pi 7}$ & $\operatorname{enp}_{1981}$ & (1) ${ }_{337}$ & $\underset{2293}{e n k}$ & ${ }_{2498}^{e k}$ & $\begin{array}{l}\text { nplk } \\
1620\end{array}$ & $e_{1572}^{e p}$ & ${ }^{\mathrm{n}} 846$ & 12.704 \\
\hline $\begin{array}{l}\text { enple } \\
\quad 2215\end{array}$ & $\stackrel{k}{2002}$ & $\begin{array}{l}\mathrm{pk} \\
2007\end{array}$ & $e_{1635}^{e}$ & $e_{1013}$ & ${ }^{n} 487$ & ${ }^{n p} 641$ & $\stackrel{e n k}{2552}$ & 13.452 \\
\hline $\begin{array}{l}\text { nk } \\
2338\end{array}$ & $\begin{array}{l}11 p k \\
2036\end{array}$ & ${ }_{2208}^{\mathrm{en}}$ & $\begin{array}{l}\text { epk } \\
3238\end{array}$ & (1) 650 & $\operatorname{enp}_{2025}$ & $\underset{2484}{\text { ek }}$ & $p_{590}$ & 15.569 \\
\hline $\begin{array}{l}\mathrm{ek} \\
2329\end{array}$ & ${ }_{368}$ & $\mathrm{nk}_{2153}$ & ${ }^{n}$ & $\mathrm{pk}_{2224}$ & $\stackrel{8}{2067}$ & $\begin{array}{l}\text { enpk } \\
2332\end{array}$ & $\begin{array}{l}\text { enp } \\
2690\end{array}$ & 15.233 \\
\hline${ }_{1748}^{n p}$ & $\begin{array}{l}\text { enk } \\
2795\end{array}$ & $e_{2625}$ & $\begin{array}{l}\text { npk } \\
1222\end{array}$ & en 2460 & $\underset{2263}{e p k}$ & ${ }^{(1)}{ }_{583}$ & 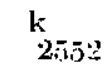 & 16.248 \\
\hline$e_{2143}$ & ${ }^{11} 886 \mathrm{i}$ & ${ }_{2716}^{\mathrm{ek}}$ & ${ }_{1926}^{k}$ & $\begin{array}{l}\text { eupk } \\
2584\end{array}$ & $p_{449}$ & en & $\underset{2236}{11 p k}$ & 16.203 \\
\hline$(1)$ & $\underset{2427}{e p k}$ & $:_{4 G 4}$ & $\mathrm{enp}_{2304}$ & $\stackrel{n k}{2299}$ & $\begin{array}{l}\text { enk } \\
1887\end{array}$ & $\mathrm{pk}_{1303}$ & $\stackrel{e}{30+4}$ & 11.153 \\
\hline en & $\stackrel{e}{2140}$ & $\underset{25.38}{\text { enpk }}$ & ${ }_{5} 04$ & ${ }_{376}$ & $k_{1466}$ & ${ }_{1545}^{n k}$ & $\underset{2588}{e p k}$ & 12.816 \\
\hline 14.385 & 14.644 & 15.068 & 14.192 & 15.004 & 12.264 & 13.723 & 17.098 & 116.378 \\
\hline
\end{tabular}

TRATAMENTOS

\begin{tabular}{rr|rr} 
(1) & 1.995 & $\mathrm{k}$ & 7.946 \\
$\mathrm{e}$ & 8.895 & $\mathrm{ek}$ & 10.027 \\
$\mathrm{n}$ & 3.289 & $\mathrm{nk}$ & 8.335 \\
$\mathrm{en}$ & 9.561 & $\mathrm{enk}$ & 9.527 \\
$\mathrm{p}$ & 1.911 & $\mathrm{pk}$ & $\mathbf{7 . 0 9 1}$ \\
epp & 8.253 & $\mathrm{epk}$ & 10.516 \\
np & 3.229 & npk & 7.114 \\
enp & 9.000 & enpk & 9689
\end{tabular}

Para uma análise estatística detalhada, as produções da testemunha não poderiam ser tomadas em consideração. Como o efeito do fósforo foi inteiramente nulo, para maior simplicidade supôs-se que o total de produção do tratamento p poderia servir como estimativa da produção da testemunha. Admitindo para ponto de partida (1) $=\mathrm{p}=1911$, e usando a fórmula

$2 \mathrm{e}_{0} \mathrm{n}_{0} \mathrm{p}_{0} \mathrm{k}_{0}=2 \mathrm{M}-(\mathrm{E}+\mathrm{N}+\mathrm{P}+\mathrm{K})+(\mathrm{NP}+\mathrm{NK}+\mathrm{NE}+\mathrm{PK}+\mathrm{PE}+$ $+\mathrm{KE})-(\mathrm{NPK}+\mathrm{NPE}+\mathrm{NKE}+\mathrm{PKE})+\mathrm{NPKE}$, obtivemos $2 \mathrm{e}_{0} \mathrm{n}_{0} \mathrm{p}_{0} \mathrm{k}_{0}=$ $=3990,1$.

Este total foi ajustado em relação às linhas e colunas que continham o tratamento (1), de forma que no final foram obtidos os dados transeritos 
no quadro 7. A análise da variância (livre da fusão das interações) está representada no quadro 8 .

Quadro 8.-Ensaio de adubação NPKE $=2^{4}$, em Ribeirão Prêto. Análise da variância, livre da fusão das interações

\begin{tabular}{|c|c|c|c|c|}
\hline Fonte de Variação & Soma de quadrados & G.I. & Quadrados Médios & $\mathrm{F}$ \\
\hline $\begin{array}{l}\text { Total } \\
\text { Linhas } \\
\text { Colunas } \\
\text { Tratamentos } \\
\text { Erro }\end{array}$ & $\begin{array}{r}40.948 .830 \\
1.862 .261 \\
1.630 .079 \\
33.114 .499 \\
4.341 .991\end{array}$ & $\begin{array}{r}59 \\
7 \\
7 \\
14 \\
31\end{array}$ & $\begin{array}{r}266.037 \\
232.868 \\
2.365 .321 \\
140.064\end{array}$ & $16,88^{* *}$ \\
\hline
\end{tabular}

Quadro 9.--Ensaio de adubação NPKE $=2^{4}$, em Ribeirão Prêto. Decomposição da soma de quadrados da parte fatorial

\begin{tabular}{|c|c|c|c|c|c|c|}
\hline \multirow[b]{2}{*}{$\begin{array}{l}\text { Trat. } \\
(1) \\
\text { e } \\
\text { n } \\
\text { en } \\
\text { p } \\
\text { ep } \\
\text { np } \\
\text { enp } \\
\text { k } \\
\text { ek } \\
\text { nk } \\
\text { enk } \\
\text { pk } \\
\text { epk } \\
\text { npk } \\
\text { enpk }\end{array}$} & \multicolumn{2}{|c|}{ Totais } & \multicolumn{2}{|c|}{ S.Q. conf. } & \multicolumn{2}{|c|}{ S.Q. sem conf. } \\
\hline & $\begin{array}{r}1.995 \\
8.895 \\
3.289 \\
9.561 \\
1.911 \\
8.253 \\
3.229 \\
9.000 \\
7.946 \\
10.027 \\
8.335 \\
9.527 \\
7.091 \\
10.516 \\
7.114 \\
\mathbf{9 . 6 8 9} \\
116.378\end{array}$ & $\begin{array}{r}116.378 \\
34.558 \\
3.110 \\
-2.938 \\
-2.772 \\
1.668 \\
-588 \\
96 \\
24.112 \\
-16.012 \\
-4.940 \\
--540 \\
-78 \\
3.785 \\
-798 \\
-18\end{array}$ & $\begin{array}{l}\text { E } \\
N \\
\text { EN } \\
\text { P } \\
\text { EP } \\
\text { NP } \\
\text { ENP } \\
\text { K } \\
\text { EK } \\
\text { NK } \\
\text { ENK } \\
\text { PK } \\
\text { EPK } \\
\text { NPK } \\
\text { ENPK }\end{array}$ & $\begin{array}{r}18.660 .240 \\
151.126 \\
134.872 \\
120.062 \\
43.472 \\
5.402 \\
144 \\
9.084 .196 \\
4.006 .002 \\
381.306 \\
4.556 \\
95 \\
223.965 \\
9.950 \\
5 \\
32.825 .393\end{array}$ & $\begin{array}{l}\mathbf{E} \\
\mathbf{N} \\
\mathbf{E N} \\
\mathbf{P} \\
\text { EP } \\
\mathbf{N P} \\
\text { ENP' } \\
\mathbf{E} \\
\mathbf{E K} \\
\mathbf{N K} \\
\text { ENK' } \\
\text { EKK } \\
\text { PK } \\
\text { EPK' } \\
\text { NPK' }\end{array}$ & $\begin{array}{r}18.660 .240 \\
151.126 \\
134.872 \\
120.062 \\
43.472 \\
5.402 \\
25.715 \\
9.084 .196 \\
4.006 .002 \\
381.306 \\
51.811 \\
95 \\
281.214 \\
168.981 \\
5 \\
33.114 .499\end{array}$ \\
\hline
\end{tabular}

Como as funções lineares (efeitos médios e interações), são as que maior interêsse oferecem, foram considerados perdidos quatro graus de liberdade no êrro e nenhum entre tratamentos, pois ficam ainda 14 funções lineares ortogonais (a interação ENPK está completamente confundida com colunas).

Dentre essas funções sòmente $\mathrm{E}^{* *}, \mathrm{~K}^{* *}$ e a interação $\mathrm{KE}^{* *}$ foram significativas, sendo KE negativa (ver quadro 9). Nos dois últimos anos várias análises foliares foram feitas, tendo havido uma resposta paralela entre as produções e os teores em potássio das fôlhas (valores de $\boldsymbol{r}$ variando entre $0,94^{* *}$ e $0,96^{* *}$ em quatro análises) com a mesma correspondência, isto é, $\mathrm{E}^{* *}, \mathrm{~K}^{* *}, \mathrm{EK}^{* *}$ (esta última negativa). Convém notar que, em duas das quatro análises foliares, $\mathrm{N}$ foi altamente significativo. As respostas entre o teor em potássio do solo, o teor nas fôlhas e as produções foram muito coerentes neste experimento.

No fim de três anos de produção, o desenvolvimento das plantas dos tratamentos (1), $\mathbf{n}, \mathbf{p}$ e np era de tal forma crítico, que se tornou neces- 
sário mudar os tratamentos excluindo-se os sem potássio, os quais foram substituídos por doses simples e dupla dêsse elemento. Ao mesmo tempo, está-se tentando melhorar as condições da testemunha por meio da aplicação adicional de estêrco.

\section{3 - ENSAIOS DE VARIEDADES}

O ensaio de variedades executado por Dafert (1) se bem que bastante rudimentar, serviu para mostrar a superioridade da variedade Bourbon sôbre a variedade comum (Nacional). Pràticamente, mais nada foi feito até 1932, quando teve ínicio o Ensaio de Variedades de Cafeeiros, o qual serviu de base para os trabalhos de melhoramento, adiante descritos.

\section{1 - ENSAIO DE VARIEDADES, DE CAMPINAS}

Foi plantado em 1932, sendo comparadas seis variedades em cinco repetições distribuídas sistemàticamente, segundo o esquema seguinte:

\section{A B C D E F B C D F A B D E F B C D E F B C D F}

onde as letras representam as variedaes: $\mathrm{A}=$ Nacional, $\mathrm{B}=$ Amarelo de Botucatu, $\mathrm{C}=$ Bourbon, $\mathrm{D}=$ Bourbon Amarelo, $\mathrm{E}=$ Sumatra $\mathrm{e}$ $\mathrm{F}=$ Maragogipe. Cada canteiro constou de uma linha de 50 covas, com quatro cafeeiros em cada uma delas.

Êsse ensaio foi analisado por Stevens (3), os dados abrangendo um total de 10 anos. $\Lambda$ experiência começou a ser colhida em 1935 mas a pequena colheita dos dois primeiros anos não foi considerada na análise estatística, na qual os resultados estudados são aquêles relativos às colheitas totais ou colheitas médias anuais. Devido às oscilações, o total foi baseado num número par de anos. A magnitude dessa oscilação anual foi medida convenientemente pela diferença entre o total de anos pares menos o total de anos ímpares. Foi obtida, em seguida, uma medida de tendência ("trend") apropriada para distinguir as diferenças no incremento das taxas de produção das variedades. Para êsse fim foi adotado o conjunto de funcões lineares ortogonais transeritas no quadro 10.

Quadro 10.-Ensaio de variedades de cafeeiro, em Campinas. Funções lineares ortogonais

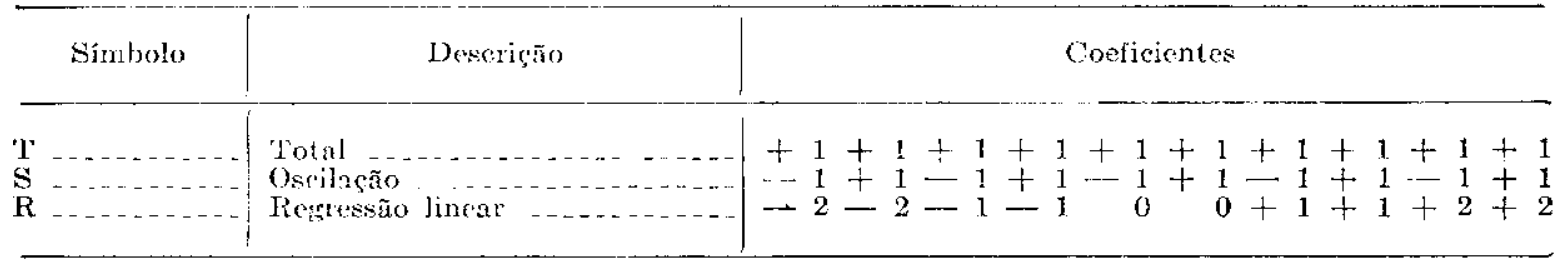

A heterogeneidade do solo foi eliminada tanto quanto possível (separadamente para as três funções $T, S, R$,), por uma análise da covariância. 
usando o número da fileira (1-30) como observação concomitante. A regressão linear não tendo sido suficiente, foram calculadas, por meio dos polinômios ortogonais, regressões até o quinto grau.

Devido à necessidade de isolar o componente "entre variedades" da soma dos quadrados e dos produtos, os coeficientes de regressão não puderam ser obtidos independentemente. As equações normais constituiram dois grupos, um dêles fornecendo os coeficientes de grau par, o outro os de grau ímpar, os polinômios de grau ímpar estando associados com as diferenças a partir do centro das fileiras, e os de grau par, com as somas. Dessa forma, o uso dos polinômios ortogonais trouxe uma simplificação muito grande nos cálculos.

Foram consideradas a regressão quadrática adequada para as funções dos totais (T) e as cúbicas para os componentes (S) e (R) e, para uniformidade, foi adotada uma equação de regressão cúbica em cada caso. Os resultados para a primeira das três funções ( $\mathrm{T}$ ), estão citados nos quadros $11 € 12$.

Quadro : 11.-Ensaio de variedades de cafeeiro, em Campinas. Análise da covariância para a parte relativa a função $\mathrm{T}$

\begin{tabular}{|c|c|c|c|c|c|c|c|}
\hline \multicolumn{3}{|c|}{ Análise Original } & \multicolumn{2}{|c|}{ Regreseño } & \multicolumn{2}{|c|}{ Analise Final } & \multirow{2}{*}{ Q.M. } \\
\hline & S.Q. & G.I. & S.Q. & G.I. & S.Q. & G.L. & \\
\hline $\begin{array}{l}\text { Variedades }-1 . \\
\text { Resto- }\end{array}$ & $\begin{array}{r}1.343 .132 \\
498.983\end{array}$ & $\begin{array}{r}5 \\
24 \\
\end{array}$ & 411.502 & 3 & $\begin{array}{r}1.286 .219 \\
87.481\end{array}$ & 2.5 & $\begin{array}{r}257.244 \\
4.166\end{array}$ \\
\hline Total $\ldots \ldots$ & 1.843 .115 & 29 & 469.415 & $\overline{3}$ & 1.373 .700 & 26 & . \\
\hline
\end{tabular}

A equação de regressão para a função $\mathrm{T}$ foi :

$\mathrm{y}=1032,4+6,351_{1}-0,462 \epsilon_{2}+0,092 \epsilon_{3}$

Quadro 12.-Ensaio de variedades de cafeeiro, em Campinas. Análise de regressão modificada para os resíduos (função $T$ )

\begin{tabular}{|c|c|c|c|c|}
\hline & & Soma de qizadrudos & Quadrados madios & G.I.. \\
\hline $\begin{array}{l}\text { Regressâo } \\
\text { Regressơrs: } \\
\text { Regressão }\end{array}$ & \multirow[t]{2}{*}{$\begin{array}{r}1.0 \text { grau } \\
1.0 \text { graus } \\
2 .^{\circ} \mathrm{giau}\end{array}$} & $\begin{array}{r}345.497 \\
347.163 \\
64.389\end{array}$ & & $\begin{array}{l}1 \\
2 \\
1\end{array}$ \\
\hline Resto & & $\begin{array}{r}411.302 \\
87.481\end{array}$ & 4.166 & $\begin{array}{r}3 \\
21\end{array}$ \\
\hline Total dentr & & 498.983 & & 21 \\
\hline
\end{tabular}

Foram calculados os limites fiduciais de $80 \%$ para as médias ajustadas (base de uma fileira por ano), eujos dados se eneontram no quadro 13. 
Quadro 13.-Ensaio de variedades de cafeeiro, em Campinas. Produção das variedades, corrigidas na base de fileira, por ano

\begin{tabular}{|c|c|c|c|}
\hline Variedades & Média não corrigida & Média corrigida & Intervalo fiducial $80 \%$ \\
\hline $\begin{array}{l}\text { A } \\
\text { B } \\
\text { B } \\
\text { C } \\
\text { D } \\
\text { E } \\
\text { F }\end{array}$ & $\begin{array}{r}84,2 \\
83,1 \\
12,5 \\
134,5 \\
107,4 \\
83,7\end{array}$ & $\begin{array}{r}87,9 \\
85,2 \\
127,0 \\
133,6 \\
105,3 \\
80,4\end{array}$ & $\begin{array}{r}81,1 \\
81,1 \\
123,2 \\
129,8 \\
101,5 \\
76,6\end{array}$ \\
\hline
\end{tabular}

A média das variedades foi subtraída da produção de cada canteiro, e daí calculatos os limites de confiança com probabilidade de 2,5\%, para os polinômios do $3 .^{\circ}$ grau das três funções $\mathrm{T}, \mathrm{S}$ e $\mathrm{R}$. Os pontos obtidos sugerem que não é desarrazoado supor que as variações restantes sejam devidas ao acaso.

As conclusões de Stevens foram as seguintes:

a) apesar de haver grandes diferenças entre as variedades, não existiu diferença significativa entre elas quanto à amplitude de oscilação, isto é, o acréscimo de produção nas melhores variedades foi o mesmo, tanto nos anos de grande como nos de pequena produção;

b) o delineamento sistemático falhou na eliminação da heterogeneidade do solo para a comparação das variedades; o defeito do delineamento pôde ser removido pela análise adequada da covariâneia com o número de fileiras.

\section{4 - TRABALHOS DE MELHORAMENTO}

Os projetos de seleção nas variedades Bourbon, Nacional e Maragogipe, foram iniciados pela colheita individual, por muitos anos, em talhões de um pé por cova, plantados com essa finalidade. Foram selecionadas as plantas mais produtivas, as quais originaram, por autofecundação, uma série de progênies. Estas foram plantadas em Campinas, Ribeirão Prêto, Pindorama e Mocoea, em linhas de 20 plantas, colhidas individualmente. A partir de 1945, o estudo da descendência dèssas plantas foi feito na forma de ensaios regionais.

Estes ensaios foram grupados em séries, o delineamento em cada uma delas dependendo da ênfase dada a um determinado problema, sempre subordinado ao objetivo principal de seleção para produção. Assim, na 1. série dêsses ensaios compararam-se progênies provenientes de diversas variedades de cafeeiro em condições de sol e sombra. Nas séries seguintes outros problemas foram abordados, tais como comportamento das plantas selecionadas quando plantadas em covas com maior número de plantas; variabilidade genética e progresso de seleção. 


\section{5 - ENSAIO DE PROGENIES AO SOL E A SOMBRA}

O delineamento utilizado foi o retículo quadrado (lattice square) $5 \times 5$ balanceado, com três repetições ao sol e três à sombra. Os canteiros contêm 16 plantas em quadrado de $4 \times 4$, as covas espaçadas de $3,00 \times 3,00$ m com uma planta por cova. Usou-se uma bordadura de três linhas para o conjunto de três repetições, de forma a se ter na parte sombreada uma bordadura também para as árvores de sombra.

Êstes experimentos foram instalados em cinco localidades e um resumo dos resultados obtidos se acha no quadro 14, no qual foram incluidos os ganhos em precisão resultantes da comparação em relação à análise como blocos ao acaso.

Quadro 14.-Produções e eficiência de quadrados reticulados plantados em diferentes.

Estações Experimentais

\begin{tabular}{l|l|l|r|r|r|r|r}
\hline \multicolumn{1}{|c|}{ Localidade } & $\begin{array}{l}\text { Trata } \\
\text { mentos }\end{array}$ & $\begin{array}{r}\text { C.V. } \\
\%\end{array}$ & $\bar{x}$ kg & $\mathrm{s}^{2}$ (b.a.) & $\mathrm{s}^{2}$ (lat.) & $\begin{array}{c}\text { Eficiencia } \\
\%\end{array}$ \\
\hline Mococa \\
Jaú
\end{tabular}

São notáveis as diferenças de produção entre sol e sombra. A eficiência média foi de $119,4 \%$ à sombra e de $129,9 \%$ ao sol, com o valor médio geral de $124,6 \%$.

Com as baixíssimas produções obtidas, a eficiência em relação ao café sombreado perde grande parte de seu valor. Para o café ao sol o ganho em eficiência foi bastante compensador, salvo em Pindorama.

\section{1 - ENSAIO DE VARIEDADES COMERCIAIS}

Êste ensaio foi plantado em 1949 em Monte Alegre, em blocos incompletos, equilibrados, 10 variedades, seis repetições, $\mathrm{k}=4, \mathrm{~b}=15, \lambda=2$, canteiros de 10 covas em linhas com três plantas por cova. Êste delineamento foi adotado por tratar-se de zona montanhosa, e mostrou-se muito eficiente na eliminação das diferenças entre blocos.

\section{5,2 - ENSAIO DE PROGENIES N. 1}

O ensaio de progênies n..$^{\circ}$, plantado em Campinas em 1950 , consta de dois quadrados reticulados simples, $4 \times 4$, balanceados, independentes (balanced lattices), com cinco repetições, canteiros de quatro plantas, colhidas 
individualmente. Um dos latices contém dois haplóides duplicados e o híbrido $F_{1}$ entre as duas plantas originais.

\section{3 - ENSAIOS REGIONAIS DE PROGANIES}

Foram plantados nas diferentes estações experimentais, o delineamento utilizado tendo sido um quadrado reticulado (lattice) triplo, $10 \times 10$, com três repetições de cada grupo perfazendo um total de nove repetições. Cada grupo de progênies de uma variedade tem a variedade primitiva sem seleção, como contrôle. Como unidade experimental - (canteiro) foi considerada uma única cova com quatro plantas. $O$ projeto foi iniciado em 1951. Êste experimento visa estudar o comportamento das progênies nas diferentes regiões em condições normais de cultivo.

\section{4 - NOVOS ENSAIOS DE PROGENIES}

A partir de 1951 foram instalados os ensaios de progênies de números 2 a 23. Estes experimentos foram plantados em diversas estações experimentais, com delineamentos em blocos ao acaso, com 20 repetições e número variável de progênies. As unidades experimentais (canteiros) também aqui são de uma única cova, porém sòmente com uma planta por cova. Mais recentemente (E. P. 23), quatro das 20 repetições foram plantadas a quatro pés por cova, visando-se estudar simultâneamente o comportamento das linhagens nas condições normais de cultura.

\section{6 - OUTROS ENSAIOS}

Além dos problemas enumerados neste trabalho, outros têm sido abordados, quais sejam, a comparação de cavalos, profundidade de plantio, espaçamento entre plantas na cova e entre covas, poda, sistema de transplantação, tratos culturais diversos etc.. Sua apresentação detalhada não é possível, no presente trabalho.

\section{1 - ENSAIOS DE ESPAÇAMENTO}

Nos primeiros experimentos de espaçamento foram considerados, conjuntamente, o problema do número de pés por cova e o de espaçamento. Foram instalados respectivamente em Campinas (1932) e em Pindorama e Ribeirão Prêto (1936). Os delineamentos utilizados foram sistemáticos. Mais tarde o problema foi novamente estudado, devido ao aparecimento da variedade Caturra, de porte menor do que as antigas e, mais recentemente ainda (1953), o problema está sendo considerado sob um aspecto trifatorial, em que se fixou o espaçamento entre linhas (visando à mecanização) e variaram o espaçamento entre covas, número de plantas por cova e níveis de adubação. Utilizou-se um delineamento $3 \times 3 \times 3$, em blocos de nove. 


\section{2 - TAMANHO DE PARCEIAS}

O problema do tamanho de parcelas foi abordado em relação a um caso específico. Em 1954 foi planejado um experimento de adubação com canteiros de 16 covas, onde seriam colhidas as quatro centrais. A utilização de sòmente $1 / 4$ das plantas do experimento é pouco econômica e, como alternativa, foi sugerido o uso de canteiros de 25 covas em que as nove centrais seriam utilizadas. Nas condições de trabalho com o cafeeiro neste Instituto é muito difícil o cálculo do custo das diferentes operações; sabemos, não obstante, que a maior parte das despesas é proporcional à área do experimento. Dessa forma, fixando-se a mesma área para os dois esquemas a serem comparados, a eficiêneia entre os dois delineamentos será o critério decisivo.

O talhão de seleção de Bourbon, referido nos trabalhos de seleção, foi escolhido para essa comparação, utilizando-se para êsse fim os totais de 10 colheitas das 1.000 plantas que o constituiam. Estas foram subdivididas em blocos compactos de 10 parcelas cada. Com quatro plantas úteis por parcela, 960 plantas constituindo seis repetições foram utilizadas. No delineamento alternativo, quatro repetições abrangeram os 1.000 cafeeiros.

Os resultados obtidos (2) estão transcritos no quadro 15.

QuADro 15.-Estudo sôbre o tamanho de parcelas para experimentação com o cafeeiro.

Análise da variância dos dois esquemas

\begin{tabular}{|c|c|c|c|c|c|c|}
\hline & \multicolumn{3}{|c|}{$\begin{array}{l}4 \text { plantas úteis } \\
960 \text { covis }\end{array}$} & \multicolumn{3}{|c|}{$\begin{array}{l}9 \text { plantas úteis } \\
1.000 \text { covas }\end{array}$} \\
\hline & Q.M. & G.I. & $\mathbf{F}$ & Q.M. & G.L. & $\mathbf{F}$ \\
\hline \multirow[t]{2}{*}{$\begin{array}{l}\text { Entre blocos } \\
\text { Dentro de blocos } \\
\text { Total }\end{array}$} & $\begin{array}{r}3.150 \\
784\end{array}$ & $\begin{array}{r}5 \\
54 \\
59\end{array}$ & $4,02^{* *}$ & $\begin{array}{l}8.569 \\
3.648 \\
\end{array}$ & $\begin{array}{r}3 \\
36 \\
39\end{array}$ & 2,35 \\
\hline & \multicolumn{3}{|c|}{$\begin{array}{l}=\frac{100 \sqrt{784,5}}{200,7} \\
=13,9 \%\end{array}$} & \multicolumn{3}{|c|}{$\begin{aligned} \text { C.V. } & =\frac{100 \sqrt{3.647,7}}{451,5} \\
& =13,4 \%\end{aligned}$} \\
\hline
\end{tabular}

Sòmente os blocos formados com as parcelas menores foram eficientes na eliminação das diferenças de fertilidade. Como medida da eficiência entre as duas situações foi tomada a relação

$E=\frac{\left(n_{1}+1\right)\left(n_{2}+3\right) s_{2}^{2}}{\left(n_{2}+1\right)\left(n_{1}+3\right) s_{1}^{2}}$

onde

$\mathrm{s}_{1}^{2}=\frac{\mathrm{Q} \mathrm{M}_{1}}{\mathrm{r}_{1} \mathrm{k}_{1}^{2}}$

(variância média de $\mathbf{r}_{1}$ canteiros, expressa na base de uma cova). 
Como os canteiros menores utilizam sòmente $96 / 100$ da área considerada no outro caso, êsse valor foi corrigido fazendo-se uso do fator $6 \times 1000 / 960$. A eficiência final é : $\mathrm{E}=(140,22)(1000 / 960)=146,06 \%$.

Em face dêsses resultados foi preconizada, para o experimento em aprêço, a utilização de canteiros de $4 \times 4$ covas, com quatro covas úteis, as covas marginais devendo ser colhidas em separado de forma a permitir, posteriormente, sua inclusão na análise do experimento, se isso se mostrar conveniente.

\section{DESTGAS AND ANAT YSIS OF COFFEE EXPERIMENTS}

\section{S U M M A R Y}

An outline is given of the designs and procedures of statistical analysis followed in coffee experiments at the Instituto Agronômico de Campinas. Four groups of experiments are considered: 1) fertilizer tests; 2) varictal trials; 3) progeny tests; and 4) miscellaneous experiments.

Under 1) the writers discuss old experiments with systematic layouts and more recent ones with randomized designs. A factorial experiment supplied conelusive results within a few years. The problem of changing some of the treatments arose in one of the experiments, and the solution proposed by the writers is discussed.

Under 2) the treatment of data used by W. L. Stevens (1949) in the analysis: of a systematic experiment comparing coffee varieties is commented in detail.

The evolution in designs used for progeny comparisons is discussed under 3 ). In early tests progenies were compared on the basis of rows of 20 plants without replications; later the designs were changed to replicated plots of 4 plants per plot, and more recently to plots of a single plant with a higher number of replications.

The results of spacing trials and of tests comparing several methods of planting coffee are discussed under 4.) The plot size for coffee experiments is also discussed, based on individual yield records from a planting of the Bourbon variety.

\section{LITERATURA CITADA}

1. DAFERT, F. W. III-Estudos sôbre a cultura do cafeeiro. In Relatório annual do Instituto agronômico, 1894 e 1895. São Paulo, Tipographia da Companhia Industrial de São Paulo, 1896. p. 77-102.

2. FRAGA, C.G. (júnior), CONAGIN, A. \& ARRUDA, H.V. Eficiência de canteiro para experimentação com cafeeiros. In Seminário de Estatística, 10.0, Campinas, Instituto agronômico, 1954. p. 63-68. [Mimeografado]

3. STEVENS, W. L. Análise estatística do ensaio de variedades de café. Bragantia. $9:[103]-123.1949$ 